Rupkatha Journal on Interdisciplinary Studies in Humanities (ISSN 0975-2935), Vol. 10, No. 1, 2018 Special Issue on "Interrogating Cultural Translation: Literature and Fine Arts in Translation and Adaptation" In collaboration with the Department of English, Amrita Vishwa Vidyapeetham Guest-edited by Dr. Hari M G, Amrita Vishwa Vidyapeetham, Coimbatore, India DOI: https://dx.doi.org/10.21659/rupkatha.v10n1.04 Full Text: http://rupkatha.com/V10/n1/v10n104.pdf

\title{
Reconsidering Performativity, Performance and Imagination: A Possibility in Erasing the Difference
}

\author{
Tapaswi H M \\ Doctoral research scholar, Manipal Centre for Philosophy and Humanities (MCPH), \\ MAHE.ORCID: oooo-ooo2-6867-6o88_Email:tapaswi.hm@gmail.com
}

Received October 30, 2017; Revised January 26, 2018; Accepted January 30, 2018; Published February 04, 2018.

\begin{abstract}
:
The overarching history of the term 'performativity' seems to have undergone variety of meaning starting from linguistic studies to gender. This variation in meaning, however, seems to differentiate the term 'performativity' from the other term which has the same root word, i.e. 'performance'. The association between 'performativity' and 'performance' doesn't seem to be studied extensively with reference to theatre. This article tries to examine the possible connection between these two terms and the role of imagination in the process of connecting these two terms. Taking into the account the idea of transformation of actor into a character and the role of imagination this article examines the subtleties of performance and performativity. The article discusses this connection with the help of an example from the mid-sixteenth century.
\end{abstract}

Keywords: Performativity, performance, imagination, gender, actor, audience.

\section{Introduction}

The three terms - imagination, performativity, and performance seem to be closely linked in their origins but are they representing similar conceptualisations? The term 'performativity' has been coined in the late twentieth century. It has been undergoing a lot of variations across 'the disciplines from the last couple of decades in its interpretation. Scholars who used 'performativity' in their theories have interpreted this term in many ways. One such understanding comes from the point of view of theatre studies. As soon as the term performativity enters the scope of theatre, it accompanies another term, called 'performance'. The very nature of these two terms is in contradiction. The contradiction involves the different ways in which these two terms are understood. That is, performativity, in the words of Miller (2007, p. 220), refers to the features of the performance, whereas performance is the end product of certain set of actions which have the intentionality 'to show' some idea (Schechner, 2013, p. 28). This contradiction needs to be resolved using another concept, imagination, which has been acquainted with theatre for many centuries.

The essential elements that constitute a theatre performance are audience, actors, script, stage setting, properties, director, and so on. The contemporary experimental theatre

(C) AesthetixMS 2018. This Open Access article is published under a Creative Commons Attribution Non-Commercial 4.0 International License (http://creativecommons.org/licenses/by-nc/4.0/), which permits non-commercial re-use, distribution, and reproduction in any medium, provided the original work is properly cited. For citation use the DOI. For commercial re-use, please contact editor@rupkatha.com. 
performances often challenge these elements through experimentation without audience, or by removing the psychological gap between the audience and the actors. The avant-garde movement ${ }^{\mathrm{i}}$ in theatre, which was started in late $19^{\text {th }}$ century is responsible for the experimentation in theatre.

While is it easy to understand the tangible elements of a performance, it is also important for us to foreground the interior spaces of the performer audience and their relationship to one another. The idea of performativity becomes important to understand this invisible part of any performance.

The first part of the paper deals with the understanding of performance, performativity and Imagination, whereas in the second part, we shall discuss the dissolving the difference in the imaginative space of the actor and the audience with examples.

\section{Performativity and Performance}

The term performativity in linguistic studies refers to the sentences which fall under the category of 'speech-act'. It was Austin who used the term 'performative' - which is later transformed as performativity - in the linguistic studies. In his understanding of the term performativity, traces out the etymological origins and notes that it is a noun for the verb 'action' or 'perform' (Austin, 1962, p. 6).

Online Etymology Dictionary (n.d.) notes that "the term 'performance' meant "a thing performed" in the $16^{\text {th }}$ century, "action of performing a play, etc." in the $17^{\text {th }}$ century and "a public entertainment" in the $18^{\text {th }}$ century". It also notes that the root word for performance is 'perform'.

Therefore, from the etymological understanding of the term 'performativity', it is clear that the root word for both 'performativity' and 'performance' is the word 'perform'. Miller (2007, p. 220) in his paper, notes that "Performativity," though not a word but a neologism, must mean the quality of a performance, or the condition of someone who is capable of performing or, perhaps, the object of investigation in "performance studies".

Miller notes that Schechner is responsible for the development of the term performance as a discipline. For Schechner 'performance' is an action in many areas such as ritual, sex, everyday life, theatre, sports, technology, business, art, and popular entertainment (Schechner, 2013, p. 31). Therefore, on one hand, the performance is a conscious act, where the performer is aware of the actions which are performed. On the other hand, the term performativity refers to the characteristic nature of such a performance, according to Miller (2007, p. 220).

Judith Butler, in the early twenty-first century, peels away the nature of the term performativity and infuses a unique sense which differentiates 'performativity' from 'performance' according to their nature. Though there are many scholars who differentiate the idea of performance from performativity, I refer to Butler here because of the lucidity in her argument about the differentiation. In the preface to the book "Gender Trouble", Butler (2010) notes

$[\mathrm{P}]$ erformativity is not a singular act, but a repetition and a ritual, which achieves its effects through its naturalization in the context of a body, understood, in part, as a culturally sustained temporal duration. (p. xv)

To understand the performative aspect of gender on stage, Butler, through using the concept from J.L. Austin, argues that the performativity of gender is not 'being' on the stage, rather it is 'doing'. Since this is the case, the subject is 'done' by the gender, according to Butler (Salih \& Butler, p. 91). She also adds that it is not a volitional act by an agent who can choose to perform 
his/her gender, rather it is the gender which chooses the agent. This nonvolitional act implies that in the case of performativity the subject is not aware of the performative transformation. Therefore, performativity is an effect, not a cause according to Butler (Salih \& Butler, 2011, p. 91).

The arguments about 'performativity' and 'gender' by Butler seem to suggest that performativity of gender involves certain political implications which are related to the identity of gender. Moreover, in my understanding of gender performativity, it is an act which has political implications and at the same time, unlike performance, it is an involuntary act where the actor or the subject of such action is merely a medium for certain conditions.

Additionally, the usage of the word 'done' in Butler's definition of performativity of gender, i.e. the subject is 'done' by the gender, contains many philosophical underpinnings. In one sense, it denotes the process of becoming (Salih, 2002, p. 46), whereas one can also understand the term 'doing' as the process of construction. In the case of gender, the subject is becoming the gender, or the subject is constructed by the gender. If this is the case, what is it which makes one lend his/her body as a medium? How does one get into the act of performativity? Salih understands these questions with reference to Butler's works. She (2002) notes

Butler claims that gender is a 'choice' [...], an idea that is not quite as straightforward as it might appear, since by 'choice' Butler does not mean that a 'free agent' or 'person' stands outside its gender and simply selects it. [...] Instead, Butler asserts that ' $[t]$ o choose a gender is to interpret received gender norms in a way that organizes them anew. (p. 46)

However, the 'choice' of gender leads the subject into the construction of chosen gender. Butler, in her earlier works including the book 'Gender Trouble', believed that both are the same (Salih, 2002, p. 63). But as noted by Salih (2002), Butler in an interview in 1993, notes the difference between these two terms by noting that 'performance presupposes a pre-existing subject, performativity contests the very notion of the subject' (p. 63). How can we examine the possible connection between 'performativity' and 'performance'?

The above discussed arguments of Butler, Miller, Schechner, and Austin, seem to be interconnected with each other. The common factor in all these arguments, on both performativity and performance, is that 'performativity constitutes performance'. According to Miller and Austin, it is very clear, whereas Butler's argument of 'performativity' seems to connect the entire act with Schechner's idea of 'performance'. Though it is not very explicitly discussed in their theories, one can read performativity and performance in a way, where one constitutes the other. However, the study of these terms as distinct from each other, renders them unamenable to any combined understanding.

Here I claim, that the idea of imagination plays an imperative role in the constitution of performance. Scholars across cultures have discussed extensively on the function of imagination in many fields. Considering the scope of the imagination is very vast, let us understand the idea of imagination in Indian philosophical context.

\section{Imagination: A Brief Sketch}

The appreciation of art, perhaps, is proportionated with the space it provides for the audience to imagine. For example, in the case of a theatre performance, audience go back to the performance of the same script several times. The reason for watching the performance of same script several times is the imagination of the actors. Hence, the audience may get to see and imagine many 
nuances in each performance of the same script. In Indian Poetics, this imagination of the actors, as well as the audience, is discussed under the terms pratibhā, kalpanā, bhāvanā and so on.

Bhatta Tota uses the word 'Pratibhā' to account the term imagination. In his book "Kāvya Kautuka" he defines the concept pratibhā as the consciousness (prajňă) which helps in perceiving and creating new things. ii The consideration of this definition triggers us to think that the idea of imagination consists of the experience of past (smrti) and present (buddhi) and the prediction of future (mati) (Shreekantaiah, 2001, p. 134). In performing a character, the actor uses his/her past experiences and the experience of the present world, and thus he/she presents the character using this consciousness which also involves a certain amount of prediction of future, since the performance is not a consequence of one day. Therefore, the importance of these three experiences is essential to an actor to present a character on stage.

Imagination (pratibhā) is further divided by Rajashekhara into two types - Bhāvayatrī Pratibhā (Receptive Imagination) and Kārayatrī Pratibhā (Creative Imagination) (Parashar, 200o, p. 46). According to Rajashekhara, the former is the imagination of the receiver or the spectator whereas the latter is the imagination of the author or the creator of the art form. Consider an example from a theatre performance. An actor who performs a character imagines the character and performs using her creative imagination (Kärayatrī Pratibhā). To enact the character, she requires plenty of experience from her everyday life. For instance, what is it to be the character, what is it to act as a character and so on. He can gather certain behaviors of the character from the script, from the observation in her life, from the testimony by others, and from the imitation of a model person. The consciousness (prajň $\bar{a}$ ) which he requires in presenting the character considers all gathered data and creates an enactment which is very unique. The process of creation of a character undergoes the creativity of the actor. This creativity is called Kärayatrī pratibha by Rajashekhara. However, in this case, as a result, the audience of that performance sees the character in the actor. To see a in a male actor, the audience requires experience and, should be able to perceive it removing the other details of the actors' personal life. These details function against the imagination of the audience from the traditional point of view. ${ }^{\text {iii }}$ The question here is what are the elements that support this kind of imagination. Is it the blind imagination of the audience, or does the actor really make the audience believe that 'the actor is a real character'? The theatrical transformation as a character is initiated with the makeup and the costume of the actor. During this process, the actor thinks of the character, and of the behavior and the role that the character plays in the entire script. Therefore, an actor needs both types of imaginations to achieve mastery over the character. This imagination (pratibhā) as well plays a crucial role in building up the character, we can consider as a surface layer of imagination or primary imagination.

Furthermore, one can also observe a second kind of imagination which works as a metalayer. This layering or positioning of imagination is different from the first surface layer. That is in the first layer, actors use their creative imagination to build the role, and the audience use their receptive imagination to imagine the characters in the actors. In the second layer of the imagination, since the actors according to the traditional theories in acting are not supposed to be aware of the audience consciously, they imagine the presence of audience and they perform their roles for these imaginary audience. This kind of imagination can be seen in the case of writers as well. In the case of writers, as noted by Ong (1975, p. 10) "[i]t would be fatuous to think that the writer addressing a so-called general audience tries to imagine his readers individually." The performance of these actors/writers is thus also influenced by this meta-layered imagination which is kind of secondary imagination. 
For the audience, on the other hand, this meta-layered secondary imagination functions to see the real person stage, the actors who is present in the character, unconsciously. This is welldescribed by Stylan (2005, p.145), where he notes

When the spectator looks at the stage, he does not see a character - he sees a man or a woman, youth or age, a smile or a frown, an arm raised or a finger extended, a figure walking or dancing. Nor does he hear words - he hears song or speech, a low tone or a light one, a whisper or a shout, quick speaking or slow, rhythm or silence itself.

At this level of perception, as described by Stylan, the audience doesn't look at the character, but looks at the man or woman who is the actor on stage. This perception may lead the audience to compare the actor who is present on the stage with the other actors whom the audience has seen before. There is a judgement of the sort where "So and so plays the part of Hamlet with more finesse." This is an unavoidable sort of imagination because the audience cuts through the illusion of the stage and perceives the real. Therefore, one can observe that one layer of imagination influences another layer of imagination. At the same time, one layer of imagination is dominated by the other layer. An ideal audience, as it is described in the traditional theories on audience, is the one who can control the domination of second layer of imagination on the first layer. ${ }^{\text {iv }}$

The interesting connection one can make at this level would be that the meta-layer of imagination may lead to the idea of performativity. The actions which are influenced by the imagination of the audience may lead the actors to act unconsciously which leads the actors to be the subject of the performativity of the script or the theme which he/she is performing. The understanding of these concepts which are discussed so far can further be deconstructed with an example from a Tamil story.

\section{Imagination in Performances}

Shulman (2012, p. 156) uses the story of Simantini as an example in one of his books to discuss the idea of imagination in India. The primary source of this story, as noted by Shulman, is Piramottara Kanțam (in Sanskrit, Brahmottara Kaṇda). The story deals with the power of imagination and the transgression of the reality which is possible through imagination. I have summarized the story from Shulman here.

The plot takes place in Vidarbha, where there are two Brahmin boys - Sumedha, a son of Vedamitra, and Samavan, a son of Sarasvata. Both these boys are well-versed in the Vedas and they want to perform some chanting in front of the King of Vidarbha so that they can earn some money for their wedding. They perform in front of the King and tell him their real intention of wanting to earn money. The king jocularly orders them to go as a couple to Simantini's place. Simantini, the wife of the Nishadha king, has been worshiping Lord Shiva and Parvati every Monday; during that day, she invites many couples across the country and worships them by imagining them as Shiva and Parvati. The two friends agree reluctantly and turn themselves into a married couple by changing their appearance. Finally, they go to Simantini's place. Even though Simantini figures out that they are not an actual couple, she imagines and worships them as Shiva and Parvati. But when they come back, Samavan who was disguised as a woman has completely transformed into a woman and names himself as Samavati. Feeling lustful towards Sumedha, Samavati forces him to fulfill her lust, but Sumedha rejects and eventually gets into a forceful union with Samavan who is now turned into a woman. After they return to their place, Samavan's father gets annoyed by the transformation of his son's gender and goes to the king seeking justice. At the end, the King confesses his fault and prays to Parvati, and requests her to give one more 
son to Samavan's father as a boon. Samavan's father begets a son in his wife's womb and Samavati marries Sumedha.

In this story, we can observe two types imaginations. The first is the imagination by Simantini of the male couple as Shiva and Parvati, and the second is the imagination of Samavan as a woman. Both the imaginations, in a way, work towards the same goal which results in Samavan's transformation into Samavati. As the result of these imaginations Simantini, in the story, becomes the audience, whereas Samavan is the actor. He, in fact, acts as a woman in the story which could cause him to become a woman.

The two kinds of imagination (i.e. audience's imagination and actors' imagination) seem to have a lot of difference in their nature. The first, as we have seen in the classification of Rajashekhara, is that the receptive imagination which helps the audience whereas creative imagination helps the actors. The applicability of Rajashekhara's classification of imagination characterizes the imagination of Simantini as Bhāvayatrī Pratibhā (receptive imagination), even though she created the image of Lord Shiva and Parvati in her mind. But the nature of the creation is very subjective and restricted only to Simantini. Therefore, this kind of imagination is addressed as receptive imagination. However, the imagination of Samavan as Samavati has resulted in the transformation of gender. This creation of gender qualifies the imagination as Kārayatrī Pratibhā (Creative imagination).

The meta-layered imagination of Simantini here is affected the way she behaves with Samavan. In the story, she points out that they are fake couple. Therefore, the imagination of Samavan as Parvati, in a way, influenced the way she behaves with Samavan. This meta-layer of imagination thus becomes the point of contact of Samavan's performativity of feminine gender as Samavati and the performance of the gender as Parvati. The first layer of imagination is helped in the constitution of performance, whereas the second layer of imagination (meta-layer) helped in the performativity.

\section{Conclusion}

The example portrays the gender transformation which is subjected to the cultural construction. The gender transformation in both the cases is initiated by the imagination. To reiterate the interpretation of performativity by Butler, the subject is done by the gender. In the example, the gender of the person is transformed by the act of performativity. The imagination (pratibhā) of Samavan has transformed the set of actions he performs into the set of actions of opposite gender.

Moreover, to reconsider Miller's argument of performativity, it is an understanding of the way they behave in certain conditions which has constituted the performativity of Samavan. Additionally, the imagination (pratibhā) of the self as other, in those particular conditions, eventually resulted in the transformation of gender.

What are the connections among imagination, performativity and performance? On one hand, the cultural condition of the subject results in the performativity. The receptive imagination in this case is supplied by the culture which affects the way one unconsciously behaves. On the other hand, the creative imagination influences the behaviour that one performs. It is plausible that the influence of acting on his/her personal life can unconsciously change one's behaviour, which results in performativity. Therefore, one can consider the possible constitution between performance and performativity which is mediated by the role of either receptive (Bhāvayatri pratibhā) or creative imagination (Kārayatrī pratibhā). 
To understand this constitution in the aforementioned example, one can observe that in the case of Samavan there is a performativity of the gender, i.e. feminine. For Samavan, it is performativity, whereas for Simantini it is a performance. The aftereffect of their performativity, where Samavan transformed as a woman may have turned him to be performative of the feminine gender without being aware of it. It is at this level, to go back to the argument of Butler (Salih \& Butler, 2011, p.11) again, the subject is 'done' by the gender with the help of imagination. Even though Samavan's actions and performativity has taken place in his unaware state of mind, the audience of his performativity and the imagination of the audience have created their performativity as performance. That is, the meta-layered imagination of Simantini has influenced on the performance of Samavan as a woman, which in turn, the imagined gender of Samavan by Simantini has started constructing the Samavan as Samavati.

Therefore, on a concluding remark one can note that the performativity of gender which is accompanied by the imagination (which consists both layers) constitutes performance to others. As noted by Butler, the process of performative 'doing' starts with the imaginary process and turns out to be performativity. The moment it meets the imagination of the audience of that performativity, it becomes performance. As Miller also notes, the action of the subject in the case of this performance establishes the performativity whereas the result is performance. It is, thus, imagination (pratibhā) which links performativity with performance.

\section{Acknowledgement}

I thank Prof Sundar Sarukkai for compelling me to work in the field of Indian theories of imagination. I extend my gratitude to Dr Meera Baindur for guiding me to write this paper. I also thank, Dr Nikhil Govind, Dr Mrinal Kaul and other professors in Manipal Centre for Philosophy and Humanities, MAHE, for their support. I extend my thanks to Shama, Vivek, and Srajana for helping me in constructing the arguments in this paper.

The earlier version of this paper was presented in a conference "Rainbow: Re-imagining Sexuality" organised by the Centre for Women's studies, at Manipal Centre for Philosophy and Humanities, MAHE, Manipal on 18 February, 2017.

\section{Notes}

\footnotetext{
${ }^{\mathrm{i}}$ Avant-garde theatre (or experimental theatre) was the phenomenon of the late $19^{\text {th }}$ century in the Western theatre arena. As the result of the avant-garde theatre an active relationship between actors and the audience has become more prominent in theatre. This movement also opposed bourgeoise theatre which was settled down in the Western theatre. Therefore, because of avant-garde movement in theatre, the connection of society with theatre has become even more active.

ii Prajňā navanavonmeșaśálini pratibhā matā. The literal translation would be 'the awareness which is possessed of new new illumination [every time], is believed as imagination'. Translated by author. There is another usage called ullekha which means appearing, uttering and so on, as well instead of the word unmeșa. For more see (Shreekantaiayya, 2001, p. 134)
} 
iii This concept is discussed under the term "Nissangatva" (State of detaching from every endeavor). Shivarudrappa (2011, p. 9) interprets that this ability of a human being makes her be an artist and differentiates her from other people.

iv One can look at the concept of sahṛdaya explained in the commentary of $27^{\text {th }}$ chapter of Nātyaśāstra by Abhinavagupta.

${ }^{\mathrm{v}}$ For detailed story see (Shulman, 2012, p. 156).

\section{References}

Austin, J. L. (1962). How to do things with words. London: Oxford University Press

Butler, J. \& Salih, S. (2011). The judith butler reader. Australia: Blackwell Publishing.

Butler, J. (2010). Gender trouble. New York and London: Routledge.

Miller, H. J. (2007). Performativity as performance / performativity as speech act: Derrida's special theory of performativity. South Atlantic Quarterly., 106(2), 219-235. doi:10.1215/00382876-2006-022.

Ong, W. J. (1975). The writer's audience is always a fiction. PMLA, 9o(1), 9-21. doi:10.2307/461344.

Parashar, S. (200o). Kāvyamīmāìsa of rājaśekhara: Original Text in Sanskrit and Translation with Explanatory Notes. New Delhi: DK Printworld.

Performance. (n.d.). In Online Etymology Dictionary. Retrieved October 25, 2017, from https://www.etymonline.com/word/performance.

Salih, S. (2002). Judith butler. London and New York: Routledge.

Schechner, R. (2013). Performance studies: An introduction. London and New York: Routledge.

Shivarudrappa, G. S. (2011). Saundarya sameekshe. Bangalore: Kamadhenu Pustaka Bhavan.

Shreekantaiyya, T. N. (2001). Indian poetics. (N. Balasubrahmanya, Trans.). New Delhi: Sahitya Academy. (Original Work published 1953)

Shulman, D. (2012). More than real. United States: Harvard University Press.

Stylan, J. L. (2005). Drama, stage and audience. Cambridge: Cambridge University Press.

Tapaswi $\mathbf{H ~} \mathbf{M}$ is a doctoral research scholar in Manipal Centre for Philosophy and Humanities (MCPH), MAHE. He finished his Master in Arts in English Literature from Kuvempu University and Master of Arts in Philosophy from MCPH, MAHE, Manipal. His areas of interest include theatre, performance, Yakșagāna, Indian aesthetics and Indian philosophy. Currently he is pursuing his doctoral research on the Aesthetic experience of the audience in contemporary Kannada theatre performances. He is working under the guidance of Dr Meera Baindur. He is also an active member of a prestigious theatre group called Ninasam in Karnataka. 